\title{
Mechanism of Cross-border Coordination through Regional Planning for Ecological Goals
}

\author{
Jian LIU, School of Architecture, Tsinghua University, China \\ Dong SU*, School of Architecture, Tsinghua University, China \\ Yixin ZHANG, School of Architecture, Tsinghua University, China
}

\begin{abstract}
At present, the world is facing the common challenge of "sustainable development". Since 2017, the Chinese government has proposed the goal of "High-quality Development", calling for concerted efforts to balance ecological protection and economic growth, refraining from the sole GDP-oriented developing model. At the same time, China is currently undergoing an unprecedented urbanization process across the country, in which all kinds of cross-border elements interact frequently, space is developed continuously, and space demand for cross-border development encounters collaboration-conflicts and constrains. This article focuses on the conflict of water system spatial governance in the transboundary region of the Yangtze River Delta. With learning from the regional coordination mechanism formed by Randstad under the ecological goal, this paper attempts to break away from the concept of traditional spatial planning, from the perspective of "planning meta-governance" structure, structurally sorts out the regional planning of the two regions from the 1950s to the present, and conducts textual metrological analysis on more than 100 central and local policies and planning texts, alongside with spatial data and semi-structured institutional interviews in the Yangtze River Delta region of China, to find the efficiency loss and mechanism obstacle of regional spatial planning for realizing regional ecological protection goals in China and to provide institutional governance insights for crossboundary planning of regional sustainable development.
\end{abstract}

\section{Keywords}

Cross-border coordination, Ecological goal, Regional planning, Planning meta-governance, Planning institution, Yangtze River Delta

\section{The Dilemma of Collective Action in Transboundary Regional Ecological Governance}

Under the global sustainable development goals, how to balance economic development and ecological environmental protection in highly urbanized areas is a main development problem faced by all countries in the world. In recent years, after China has experienced severe environmental pollution caused by rapid urbanization, governance transformation has begun at the institutional level, and the goal of "highquality development" has been proposed, including ecological priority, green development, and the overall management of landscapes, forests, fields, lakes and grasses. A new agenda focusing on the symbiosis of development and protection, has become the direction of space governance in the new era.

Meanwhile, regional development represented by urban agglomerations and metropolitan areas is an important feature in the contemporary urbanization process. Space develops continuously across administrative boundaries, and various elements frequently interact across borders, and space governance has also begun to cross borders and wide areas. Due to the "fence effect" attribute of crossboundary administration, cross-border areas always involve a large number of differentiated stakeholders, man-made political factors, limited understanding of complex ecosystems, and the multidimensional time and space scope of biophysical processes. Therefore, to achieve common regional 
development goals, cooperation and collaboration are usually considered the best choice to solve these problems (BODIN Ö, 2017), and regional coordinated governance has become an urgent demand. But for many years, the problem of "coordination" has always existed, and the issues are highly similar: contradiction between the administrative bodies is difficult to be resolved, and the design of the coordination mechanism is facing failure. As a result, the conflict between development and protection has become a typical problem that needs to be resolved in the process of wide-area transformation.

Take the regional water system management of the Yangtze River Delta in China as an example. The Yangtze River Delta has a population of 227 million people and an area of 358,000 square kilometres. It is not only China's richest area per capita, but also a pioneer area of regional integration, and is one of the six world urban agglomerations recognized internationally. The area now includes Shanghai, Jiangsu, Zhejiang, and Anhui provinces, and includes many economically developed cities such as Nanjing, Suzhou, Wuxi, Hangzhou, Ningbo, and Jiaxing. At the same time, as the alluvial plain before the Yangtze River enters the sea, this area contains lakes and rivers, with cross-border water systems crisscrossed, and rich in farmland resources, and natural scenery.
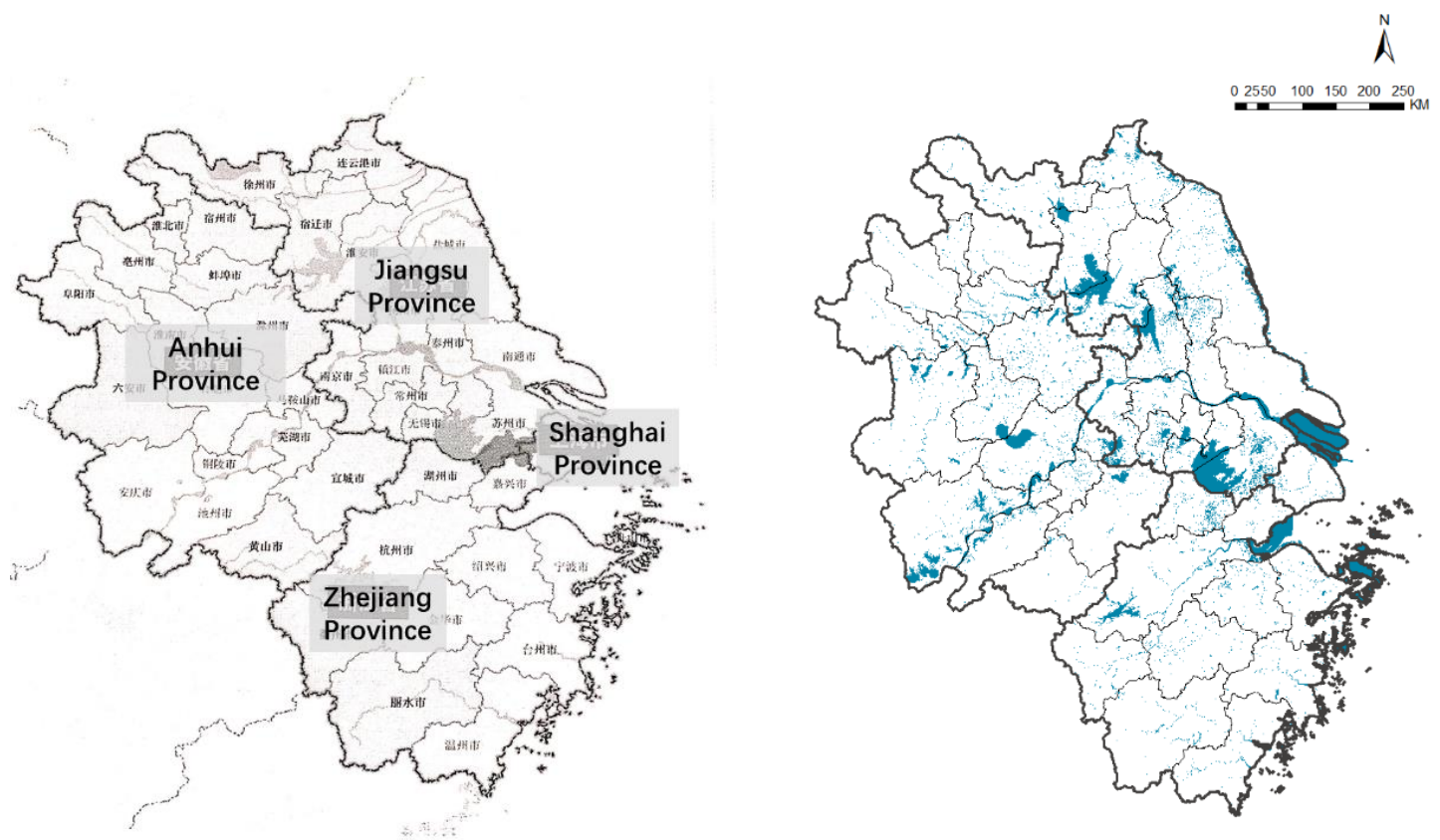

Figure 1 China's Yangtze River Delta regional administrative division and regional water system map in 2018

Source: by author

However, in the past 30 years, with the increase in urbanization and population agglomeration, human activities have severely damaged the ecological system of the region. The fierce competing for land between urban area and water system has become increasingly prominent (Han Longfei et al., 2015), leading to decline in river networks density and increase in ecological pollution. By author used land data from 1980 to 2018 and superimposed administrative boundary data to derive the area of water area, including aquifers, lakes, reservoirs, tidal flats, and beaches. It is found that the water area of the Yangtze River Delta, except for artificial reservoirs and ponds, has decreased by nearly 800 square kilometres in 30 years (Table 1 ), classified and categorized by province and city. 
Table 1 Changes in the water area of the Yangtze River Delta (unit: square kilometers). Source: by author

\begin{tabular}{|c|c|c|c|c|c|c|c|c|c|c|}
\hline 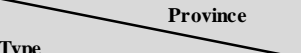 & \multicolumn{2}{|c|}{ Anhui } & \multicolumn{2}{|c|}{ Jiangsu } & \multicolumn{2}{|c|}{ Shanghai } & \multicolumn{2}{|c|}{ Zhejiang } & \multicolumn{2}{|c|}{ YRD Region } \\
\hline River and canal & -72.05 & & -153.03 & & & 2.99 & -7.78 & & -229.87 & \\
\hline Lake & & 246.42 & -49.12 & & & 1.01 & & 51.14 & & 249.45 \\
\hline Tidal flat & & & -196.78 & & -89.34 & & -24.79 & & -310.91 & \\
\hline Mudflat & & 144.46 & -320.45 & & -59.65 & & -272.73 & & -508.37 & \\
\hline Reservoirs and pit（Artificial） & & 519.6 & & 1483.66 & -2.6 & & & 526.29 & & 2526.95 \\
\hline Variation of water area & & 838.44 & & 764.28 & -147.59 & & & 272.13 & & 1727.26 \\
\hline Variation of natural water area & & 318.83 & -719.38 & & -144.99 & & -254.16 & & -799.70 & \\
\hline
\end{tabular}

In addition, cross-border ecological problems have also triggered social conflicts between administrative regions. For example, in the 1970s, the upstream cities in Jiangsu Province reclaimed the lakes, aggravating the flood disasters in the downstream areas of Hangzhou, Jiaxing, and Huzhou. Since the 1990s, due to the rapid development of small and medium-sized industries in southern Jiangsu, the problem of large industrial water discharge at the junction of Jiangsu and Zhejiang Contradictions has emerged, leading to issues like building dams by downstream citizens, drinking water diarrhea, fishermen petitioning, and dead pig rafting incidents, etc. (Figure $2 \& 3$ ).

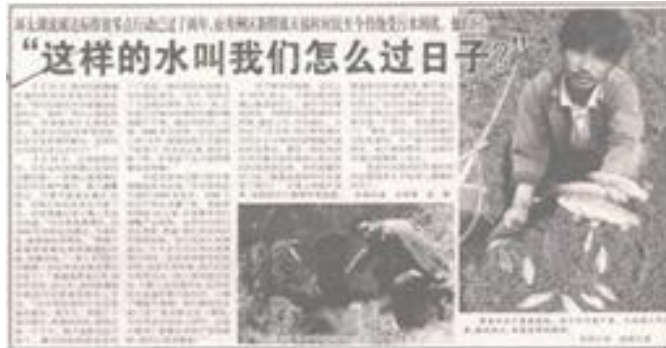

Figure 2 The newspaper reported on public opinions under cross-border water pollution :"How can we live with water like this?" Source: the local newspaper, 2001

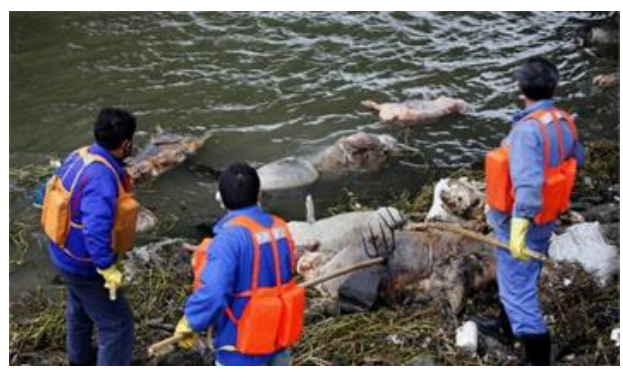

Figure 3 The dead pigs in a town of Jiaxing city in the upper reaches drift into the rivers of downtown Shanghai. Source: icpress.cn, 2013

Why are metropolitan areas less and less adaptable to the water environment? On the one hand, from the perspective of planning technology, the traditional spatial planning with administrative divisions as the compilation unit has limitations: Taking the layout of functional spaces as an example, municipal officials and planners always stand on their own level, and tend to place construction land, industrial and mining areas, and polluting industries in the lower reaches of the river and the downwind direction within the spatial scope of the administrative region, neglecting the possible effect on the adjacent areas. On the other hand, from the perspective of administrative systems, there is a significant difference between the goals of ecological environmental protection and GDP-oriented developments: environmental responsibilities have a long effective period, difficult to divide through administrative regions, and require continuous investment. These factors make environmental governance the problem of "public goods" with typical externalities features, for which the driving force for regional coordination becomes insufficient.

In addition, the institutional issues of planning are often overlooked. Over the years, Chinese planners have participated in numerous ecological city planning, green city planning, pollution prevention and control planning, environmental protection planning, and circular economy planning. But these plans are often on the shelf. The ambitious goals prompted in these plans, the advanced technologies to be adopted, and the meticulously involved projects are always on two parallel lines with the reality of a "partial improving but overall deteriorating" environment. Planning technology may not be the key factor, but the planning system and its implementation are the decisive factors (Hou Aimin, 2016). 
Why this existing planning system fails to solve regional environmental problems? In response to regional environmental issues, how is the planning governance structured, and what challenges are facing the current governance? This article, from the perspective of a holistic planning governance structure, attempts to exploring the ecological environment governance issues in transboundary areas, through combing the regional planning structure from the 1950s to the present, analysing texts from more than 100 central and local policies and plans, alongside with spatial data and semi-structured institutional interviews in the Yangtze River Delta region of China.

\section{Meta-governance structure of cross-border regional planning}

\subsection{Cross-border regional planning}

The definition of "region" has always been relatively broad. This article makes the following classifications, mainly including: 1) The concept of a large area on a macro-scale without a clear boundary. 2) The interprovincial or inter-city related areas represented by urban agglomerations and metropolitan areas are divided by administrative regions or natural basins, which contain generally clear management boundaries. For example, the spaces in national key regional strategies such as the Beijing-Tianjin-Hebei, Yangtze River Delta, and the Yellow River Basin, as well as the spatial areas in the planning of districts involving multiple cities, such as the "Hongqiao Area" in Shanghai, etc.; 3) Some specific spatial areas, such as urban and rural areas and residential areas.

"Region" in this study refers to cross-border regions: It contains any continuous space that crosses the administrative boundaries between provinces, prefectures, cities, and districts and counties, with particular attention to rapid urbanization represented by urban agglomerations. The cross-border continuous area within a region is not limited to a single regional concept between a certain administrative level.

The traditional definition of regional planning refers to the overall strategic deployment and policy guidance for the social, economic, environmental development, and spatial layout of a specific region within a certain period of time. In the field of planning, regional planning is defined as the overall deployment of development and construction goals in a certain area, and it is an important basis for urban planning to provide urban development direction and productivity layout (Hu Wen, Huang Lai et al., 2015). It includes not only the development planning for the overall strategic deployment of regional socio-economic development and construction, but also the construction layout space planning related to land development and renovation in a certain area, such as land space planning, metropolitan planning, etc. In addition, it also includes regional special plans such as environmental planning and transportation system planning.

Although different types of regional planning have their own characteristics, they are all coordinated tools for the distribution of natural and social elements in space. They are related to land development, utilization, and protection, and belong to cross-departmental regional planning (Hu Xuwei, 1982). Regional planning is one of the important governance tools for multiple entities to promote the coordinated development of cross-border regions.

\subsection{Planning meta-governance: collaborative structure}

In this article, coordination is not seen as "ideal state", but a "national governance process" to achieve a certain goal. The coordination mechanism is a platform that connects and promotes the interaction, exchange and even cooperation of various main elements. It plays a functional role in realizing rationalization and structured resource allocation among subjects in regional governance. It is also an explanation of the national governance structure and the process of national governance. 
Regarding the national governance structure, existing studies have constructed a corresponding interpretation framework, taking institutions, functions and management tools as the three elements, deconstructing the internal structure from the system of national governance to the effectiveness of national governance (Figure 4). In this framework, there are many management tools for national coordinated governance, such as economic regulation, taxation policies, and household registration reforms. Planning, as a public policy for arranging benefits, is one of the management tools used by corresponding agencies to achieve their functions.

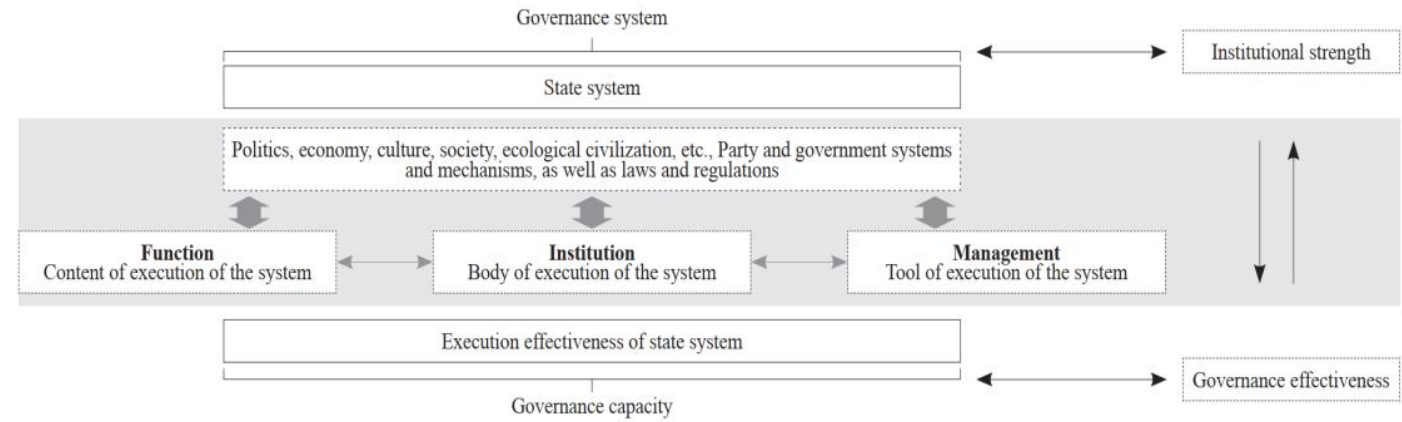

Figure 4 Analysis Model of "National Governance Structure" . Source: reference（Su D.\& Liu J, 2021)

In order to further analyse the institutional mechanism of planning governance, this paper introduces the concept of "planning meta-governance". At the beginning of this century, Jessop put forward the concept of "meta-governance", that is, "governance of governance". As the governance parties have their own positions and different interests in the process of negotiation and collaboration, it is likely that they will not be able to achieve common governance goals, which become the main source of governance failure. In order to coordinate the positions and interests of different forces and organizations and make them tend to a common goal, a starting point and axis of "governance" is needed, and the role every country (government) should play is to coordinate the interests of all parties and ensure an orderly governance process. Therefore, the use of meta-governance theory can more clearly explore the governance structure of "planning governance", that is, "planning meta-governance" from the three dimensions of planning institutions, planning functions, and planning tools under the framework of national governance structure.

\section{Phase characteristics of China's cross-border regional planning structure}

\subsection{Phase 1 (before 1980): Spontaneous formation of regional consciousness}

In 1954, the East China Bureau of the Central Committee of the Communist Party of China reported to the Central Committee, suggesting that the overall leadership of Jiangsu, Zhejiang, and Shanghai should be strengthened. The Central Committee telegraphed the approval of the establishment of the Shanghai Central Bureau, which became the earliest sprout of regional integration in the Yangtze River Delta since 1949. In 1957, in order to promote the coordinated development of industry and agriculture between regions, the Shanghai Bureau convened a meeting on economic cooperation in the five provinces of Jiangsu, Zhejiang, Fujian, Anhui, Jiangxi, and Shanghai. The economic cooperation committee was established with the approval of the central government. In 1958 and 1961, the central government established the East China Cooperation Zone and the Central East China Bureau covering 7 provinces, and the regional scope expanded again. However, until the 1980s, there were no more regionalization actions in the Yangtze River Delta. In this few regional cooperation, no substantial cross-border regional planning tools have been formed, and the effects of regional governance have failed to appear, but regional awareness has spontaneously formed from the bottom up. 


\subsection{Phase 2 (1980-2003): Temporary group establishment and planning failure}

In the 1980s, during the transition from China's planned economy to a market economy, economic factors began to flow frequently. The flow of market-oriented factors has created the demand for regional cooperation. In 1982, in response to the call for the establishment of the "Yangtze River Delta Economic Zone", the State Council issued the "Notice on the Establishment of the Shanghai Economic Zone and Shanxi Energy Base Planning Office", and established the "Shanghai Economic Zone" covering 10 cities in Shanghai, Jiangsu and Zhejiang. It became the first inter-provincial economic zone after China's reform and opening up. That year was also generally regarded as the first year of the development of regional integration in the Yangtze River Delta.

In the late 1980s, due to the rapid development of township enterprises and private economy, the economic strength of Jiangsu and Zhejiang provinces was greatly enhanced; Shanghai's status and role as the central city of the economic zone was gradually declining. At the beginning of the establishment of the economic zone, the differences between the two provinces and one city on the issue of economic cooperation reappeared. In 1986, the "Planning Office" completed the "Outline of Shanghai Economic Zone Development Strategy" and 22 plans for energy, transportation, foreign trade, technological transformation, and Taihu Lake governance. However, due to the multi-party interests involved, few programs were actually approved for implementation, and it failed to find a new path in breaking the barrier between the "economic zone" and the "administrative zone." Few programs have been implemented, failing to find a new path in breaking the barrier between the "economic zone" and the "administrative zone." In June 1988, the Shanghai Economic Zone Planning Office was abolished, and the Shanghai Economic Zone also withdrew from the stage of history. From 1992 to 2003, a joint meeting system of directors of the Yangtze River Delta City Cooperation Department, the Yangtze River Delta City Economic Coordination Committee, and economic cooperation and development forums initiated by the Shanghai, Jiangsu, and Zhejiang development and reform departments were successively established. The cross-border regional coordination structure formed at this stage was mainly composed of voluntary, open, and temporary regional cooperation organizations, namely conference platforms. The exploration of setting up planning agencies and preparing cross-border regional plans ended in failure.

At the same time, administrative barriers and geographical divisions caused by administrative divisions frequently occur in economic activities, causing negative externalities such as environmental pollution. Taking the problem of pollution in northern Jiaxing caused by printing and dyeing wastewater in Jiangsu Province as an example, the transboundary pollution of printing and dyeing wastewater in Shengze Town, Jiangsu Province began in the early 1990s. With the expansion of the production scale of the textile printing and dyeing industry in Shengze Town, a large amount of untreated sewage is directly discharged into Jiaxing. According to survey data, in 2000, the total daily discharge of sewage from the printing and dyeing industry in Shengze Town reached more than 300,000 tons, but the sewage treatment capacity was only about 100,000 tons. The water environment has deteriorated drastically. The water quality of the river at the junction of the two places has developed from a Class III state in the late 1980s to a poor Class IV in 1992, and has become a poor Class V since 1996. The average annual COD value in 1996 was $32.8 \mathrm{mgL}$, and the COD was as high as $2001.47 .5 \mathrm{mgL}$.

At the same time, the pollution area has further expanded. The area affected in Jiaxing has increased from less than 200 square kilometers in 1995 to nearly 400 square kilometers in 2000, and has spread to Shanghai. In 2000, the fishery waters in the northern part of Jiaxing City alone had a polluted area of more than $100,000 \mathrm{mu}$, with a direct economic loss of more than 56 million yuan. Due to the use of polluted water for irrigation, local agricultural production and harvests have been reduced, and rice production and paddy farming have also been endangered on a large scale. For more than ten years, the coordination between the two provinces has achieved little effect, and pollution has become more and more serious. On the government side, Jiaxing City has reported many times to the State Environmental Protection Administration, and took the initiative to send personnel to Wujiang City to negotiate; on the 
public side, they independently initiated dam-building operations to intercept transboundary sewage; on the social side, CCTV's program also exposed the discharged sewage in Shengze Town, Jiangsu Province., but the transboundary sewage problem still cannot be resolved. And even when the State Environmental Protection Administration issued a document ordering it to prohibit new printing and dyeing enterprises, the town still built a printing and dyeing enterprise park covering an area of 5,000 $\mathrm{mu}$ in the area adjacent to Jiaxing.

In this process, the state and local governments have established a number of cross-border coordination groups: such as the National Environmental Protection Leading Group, Zhejiang Environmental Protection Leading Group, and Hangzhou-Jiaxing-Huzhou Water Pollution Prevention and Control Work Leading Group. The phased "leading group mechanism" has become a coordination model with Chinese characteristics. However, the leading group is a temporary establishment, and its establishment and cancellation are determined by the event. It does not have the supervision and coordination function of the whole process, and has limited effectiveness in the treatment of lagging and long-term cross-border ecological problems. However, at this stage, the urban planning has poor control over industrial construction behaviours, mainly relying on the negotiation of the environmental protection department instead of controlling the industrial layout, and the planning tools are in a state of failure.

\subsection{Phase 3 (2004-2018): Regional planning and planning coordination}

During this period, regional cooperation in the Yangtze River Delta entered an intensive phase. In 2004, the Mayor's Meeting of the Yangtze River Delta City Economic Coordination Committee was changed from once every two years to once a year, and the "City Cooperation Agreement" was signed. In 2005, regional cooperation was promoted to the highest decision-making level, and a meeting mechanism for major leaders in the Yangtze River Delta was established. This meeting has also become the most important meeting in the coordination mechanism for cross-border regional cooperation. From 2010 to 2017, the "Regional Plan for the Yangtze River Delta Region" and "The Development Plan for the Yangtze River Delta City Cluster" were successively issued, and cross-border regional concepts such as the core area of the Yangtze River Delta Planning, the Yangtze River Delta City Cluster, and the Shanghai Metropolitan Area appeared. However, regional governance tools are presented as development plans. As there is no statutory status and responsible department, planning is not very restrictive and compulsory. It is now evaluated by local governments as "no longer needed", and the effectiveness of planning governance is relatively weak.

But at this stage, "multi-regulation integration" is also unfolding at the same time. Due to the large number of planning editions and backward data management capabilities in various regions, the effectiveness of supervision over the implementation of this policy is not strong. In 2004, Zhejiang Province began to explore the convergence model of "two plans", using the county master plan as a platform to promote "full coverage of urban and rural areas, one space map", which became the origin of China's "planning coordinated governance" practice. Since then, Beijing, Shanghai, Wuhan, Qingdao and other cities have successively merged the planning departments and the land and resources departments to establish the Planning and Land Resources Administration to realize the integration of land use planning and urban and rural planning. From 2007 to 2008, Chongqing and Guangdong launched pilot projects of "Four Regulations in One" and "Three Regulations in One" to explore a coordinated governance model that links economic development, land use, urban and rural construction, and environmental protection planning. In 2014, four national ministries and commissions began a top-down pilot project of "multiple regulation and integration" in 28 cities and counties across the country, trying to improve the level of land and space governance through the coordination of planning. 


\subsection{Phase 4: Cross-border regional agency exploration (2018-present)}

In 2018, China's national institutional reforms and the establishment of the Ministry of Natural Resources required all localities to formulate "land and space plans" through planning coordination, and China's planning system has undergone major changes. At the same time, the Yangtze River Delta region has also entered a new historical stage, and two important regional coordinated actions have taken place.

First, in 2018, the central government announced the development of regional integration in the Yangtze River Delta into a national-level strategy. The main leaders of the Yangtze River Delta region at the local level proposed the establishment of the Yangtze River Delta Regional Cooperation Office, which became the first permanent entity establishment responsible for overall cross-administrative regional cooperation in the Yangtze River Delta. The organization is mainly composed of government personnel from the four provincial administrative regions. The core management tool is to organize and compile the "Three-year Action Plan for the Integrated Development of the Yangtze River Delta" and the annual plan. The Action Plan is essentially a short-term plan for the Yangtze River Delta region, with project task selection and task responsibility decomposition as the main management tools for the plan. The tasks cover more than ten aspects such as economy, public services, ecological and environmental protection, and infrastructure, including more than 200 items of specific cross-border collaboration matters. The office is responsible for submitting to higher authorities for deliberation and promoting the implementation of cooperative projects. As a result, at the cross-border regional level of the Yangtze River Delta, a three-tier collaborative structure of decision-making, coordination, and execution levels has been formed (Figure 5). The Action Plan has become an important planning tool at the regional level.

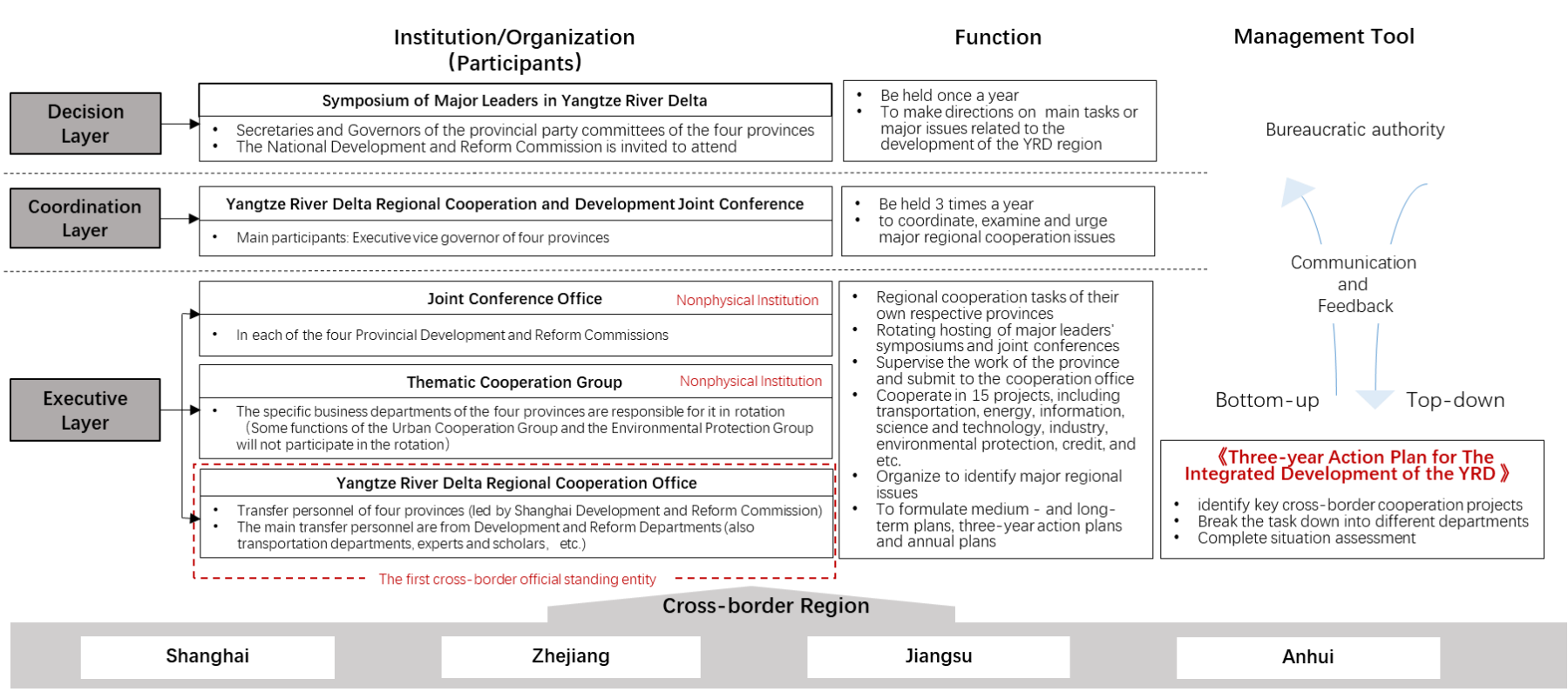

Figure 5 Three-tier coordination structure in the Yangtze River Delta. Source: by author

Second, since 2019, China issued the "integration of the Yangtze River Delta Development Plan", at the junction of three provinces and regions Shanghai, Jiangsu, Zhejiang selected two districts and one county, established the "Yangtze River Delta integration of eco-green model of development "(Figure 6), and established the Demonstration Zone Council and the Demonstration Zone Executive Committee, and started the exploration of the cross-border regional coordinated development model under the ecological protection goal. The average water network density in the demonstration area is as high as 3.5 $\mathrm{km} / \mathrm{km} 2$. The dense and richly layered lake water network has bred dense water towns and village communities, which are connected by the Taipu River Basin and the Dianshan Lake group. Jiangnan pattern, largely dominated the urban and rural Clustered space and texture qualities demonstration area. 


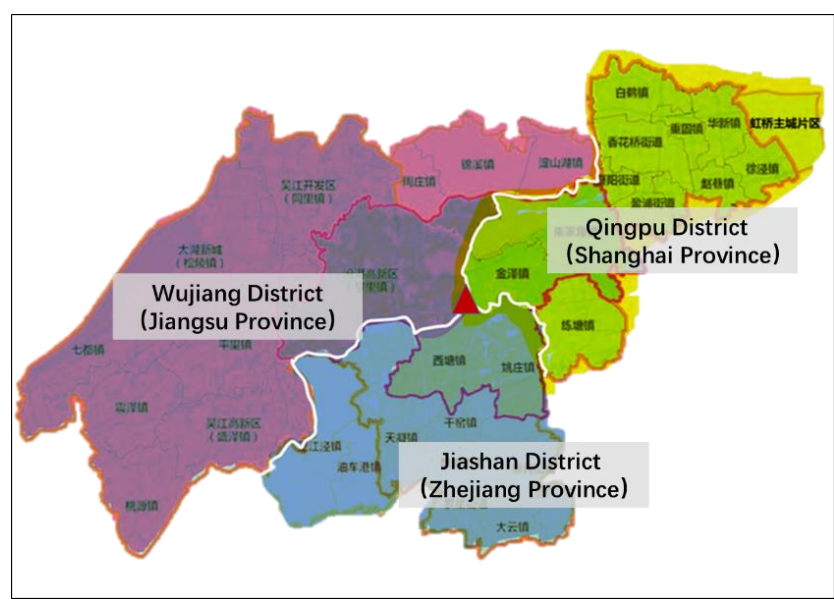

Figure 6 The administrative scope of the Yangtze River Delta Eco-Green Integrated Development Demonstration Zone. Source: by author

Also constrained by the geographical factors of dense lakes and water networks, the growth of construction land in the region is relatively restrained. However, the rapid expansion of Fenhu High-tech Zone, Yaozhuang Development Zone, Xitang Industrial Park and other areas has also broken the original spatial pattern of multi-site clusters, and the Lake District has experienced different degrees of spatial encroachment (Figure 7).

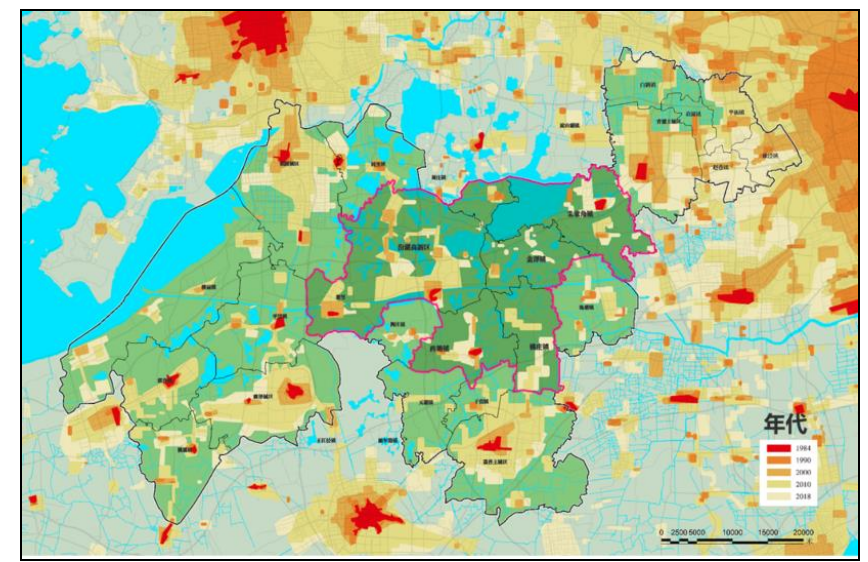

Figure 7 Expansion status of urban construction land in the demonstration zone over the years. Source: Demonstration Zone Executive Committee, 2019

In June 2020, the three provinces' natural resources departments, Suzhou City, Jiaxing City, Qingpu District, Wujiang District, and Jiashan County governments jointly organized the preparation of the "Overall Plan for the Land and Space of the Yangtze River Delta Ecological and Green Integrated Development Demonstration Zone (2019-2035)". In this version of the plan, the focus is to reflect the regional goal of ecological basement, strengthen the restriction and guidance of the water-centric ecological space on the urban and rural spatial layout, and strive to expand the regional blue and green space, becoming the first inter-provincial territorial and spatial planning jointly prepared by provincial administrative subjects in China.

On the whole, in the coordinated development of the Yangtze River Delta, the coordinated goal has changed from promoting economic cooperation to ecological green priority; at the same time, regional coordinated governance has shown phased characteristics, and the collaborative governance mechanism at each stage is different, but they all contain the use of planning governance tools. Further analysis based on the perspective of planning meta-governance reveals the changes in the use of cross-border planning agencies, planning texts and planning tools and different effectiveness evaluations (Table 2). 
Table 1 Summary of planning meta-governance at each stage. Source: by author

\begin{tabular}{|c|c|c|c|c|c|c|c|c|}
\hline \multirow[b]{3}{*}{ Stage } & \multicolumn{6}{|c|}{ The structure mechanism of Planning Meta-governance } & \multirow{3}{*}{$\begin{array}{c}\text { Other } \\
\text { mechanism }\end{array}$} & \multirow{3}{*}{$\begin{array}{l}\text { The goal of } \\
\text { regional } \\
\text { coordination }\end{array}$} \\
\hline & \multicolumn{2}{|c|}{$\begin{array}{c}\text { Cross-boundary } \\
\text { planning institutions }\end{array}$} & \multicolumn{2}{|c|}{$\begin{array}{c}\text { Cross-boundary } \\
\text { planning documents }\end{array}$} & \multicolumn{2}{|c|}{$\begin{array}{l}\text { Cross-boundary } \\
\text { planning tools }\end{array}$} & & \\
\hline & $\sqrt{ } / \mathrm{N}$ & $\begin{array}{c}\text { Effectiveness } \\
\text { evaluation }\end{array}$ & $\sqrt{ } / \mathrm{N}$ & $\begin{array}{c}\text { Effectiveness } \\
\text { evaluation }\end{array}$ & $\sqrt{ } / \mathrm{N}$ & $\begin{array}{l}\text { Effectiveness } \\
\text { evaluation }\end{array}$ & & \\
\hline Stage 1 & $\mathrm{~N}$ & - & $\mathrm{N}$ & - & N & - & A. Meeting platform & \\
\hline Stage 2 & $\sqrt{ }$ & - & $\sqrt{ }$ & - & $N$ & - & $\begin{array}{l}\text { A. Temporary organization } \\
\text { B. Meeting platform }\end{array}$ & $\begin{array}{c}\text { Economic } \\
\text { cooperation }\end{array}$ \\
\hline Stage 3 & $\mathrm{~N}$ & - & $\sqrt{ }$ & $+/-$ & N & - & $\begin{array}{l}\text { A. Strategic Cooperation } \\
\text { agreement } \\
\text { B. High-level leaders' meeting } \\
\text { C. Regular Meeting platform }\end{array}$ & \\
\hline Stage 4 & $\sqrt{ }$ & + & $\sqrt{ }$ & + & $\sqrt{ }$ & + & $\begin{array}{l}\text { A. High-level leaders' meeting } \\
\text { B. Regular Meeting platform } \\
\text { C. Permanent Establishment } \\
\text { D. Cooperation } \\
\text { E. Declaration } \\
\text { F. Coalition of private think tanks }\end{array}$ & $\begin{array}{l}\text { Eco-friendly } \\
\text { High-quality } \\
\text { development }\end{array}$ \\
\hline
\end{tabular}

\section{Regional comparison: Randstad's cross-border planning structure for ecological goals}

Randstad in the Netherlands is a cross-border area spanning the four provinces of South Holland, North Holland, Utrecht and Flevoland, including Amsterdam, Rotterdam, The Hague, Utrecht and many other small and medium-sized cities. It is a typical representative of the world's polycentric urban agglomeration. Randstad's development thinking is based on maintaining the "green heart" pattern and blue-green space. However, Randstad's economic center status and rapid urbanization continue to exert new pressure on the ecological environment. During the post-war reconstruction of the Netherlands, the population was concentrated in the Randstad area on a large scale, and major cities continued to expand outward, resulting in the blind destruction of large areas of forests, seawater intrusion, flood threats, and deterioration of the water environment. Planning and management on a regional scale has become the basic guarantee for maintaining the ecological pattern. Since the 1950s, the Dutch government has taken a series of measures to promote the environmental governance of Randstad and achieved good results. Its cross-border planning and governance structure is of value to China.

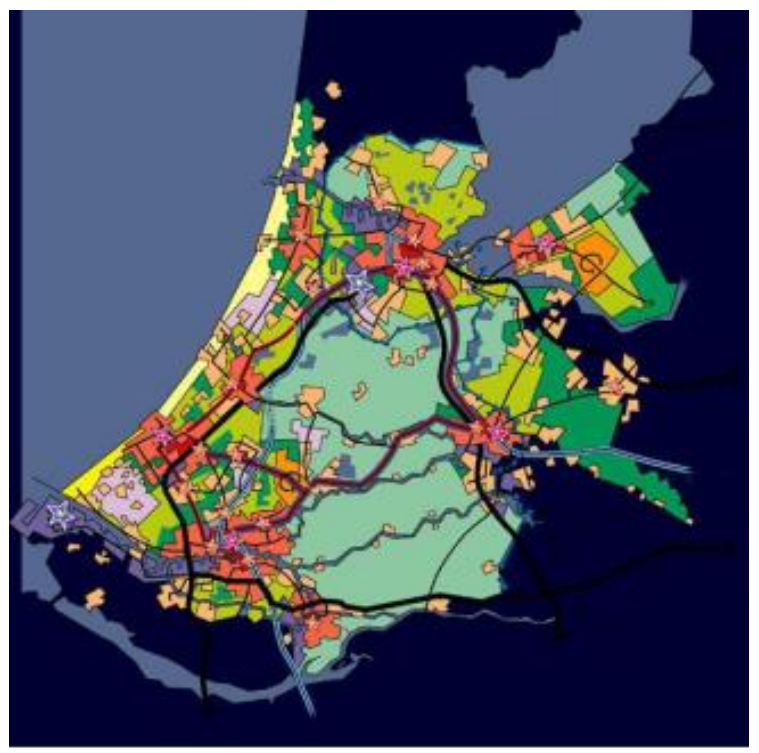

Figure 8 Overview of the Randstad. Source: Ministry of VROM, 2008 


\subsection{Planning agency: multi-centre regional collaboration network}

Unlike China, the Dutch cross-border regional coordination agency has always existed. In addition to provincial and local government departments, national-level departments are also involved, so that regional institutions can meet the function of cross-border coordination in terms of level and power. In addition, many non-governmental regional organizations are constantly strengthening regional cohesion.

Since the 1950s, the Dutch government began to establish regional joint institutions to focus on promoting regional sustainable development, so that the "green heart" was strictly protected. In 1951, the Netherlands established the National Western Work Committee, which is composed of representatives from the national, provincial and municipal government departments: including the Ministry of Economy, Agriculture, Transport, Public Utilities, North Holland, South Holland and Utrecht. , As well as cities such as Amsterdam, Rotterdam, The Hague and Utrecht, are responsible for the coordinated development of the Randstad region. In 1958, the Western Territory Planning Committee was established to be responsible for the land and space planning of the Randstad area; two regional coordination agencies, the Territorial Planning Committee, the Cabinet Territory Planning and the Environment Committee, were subsequently established. In addition to establishing a coordinating agency for the Randstad region at the national level, regional non-governmental organizations have also been established: including the Green Heart Steering Committee, the Randstad North Wing Five Cities Advisory Agency, and the Randstad Region Delegation etc.

After 1990, in addition to strictly controlling commercial and residential development, the Randstad regional coordination organization turned to the establishment of an organizational function network based on urban agglomerations, and established a regional government organization to coordinate the development of the region. For example, the Randstad Region Bureau (a regional public organization composed of provincial and major city governments, with a spatial planning committee under it), Greenheart Platform (composed of the state, provincial governments, and related administrative agencies in four core cities), Delta metropolis Association (composed of the 4 largest cities of Randstad), Administrative Committee for the Randstad (composed of the central government, the four provinces of Randstad and the 4 largest cities), the Advisory Committee of the South Wing of Randstad, etc. At the local government level, each province in the Randstad region has established a land planning committee composed of municipal government officials, land planning inspectors and social groups. Rotterdam and Amsterdam have also established a "city alliance".

After 2009, the Ministry of Housing and Spatial Planning and the Environment (VROM) were formally disintegrated, merged into the Ministry of Transportation and Water Management, and the Ministry of Infrastructure and the Environment (I\&M) was established. The spatial planning agency has undergone a transformation from the construction planning department to the environmental department, which also reflects the negative space planning thinking of the Netherlands.

Randstad's regional planning agencies fully cover the national, provincial and local levels, and reflect the full cooperation of government organizations and non-governmental organizations, forming a regional integrated cooperation model and strategic network, and jointly assume risks and continue to carry out Integrate resources within the region to cope with the ecological environmental challenges of urban agglomerations.

\subsection{Planning documents: replacing spatial planning with environmental vision}

The Netherlands mainly implements the environmental protection of transboundary areas through the preparation of national-level spatial plans. Over the years, spatial planning at the national level has undergone a transformation from planning reports to spatial strategies, and spatial planning has gradually merged into an "environmental vision", and the local level has also replaced the original structural vision and land use planning with "environmental planning". At the regional level, there are 
few independent planning documents for Randstad. "Randstad 2040 Structural Vision" is the first officially approved national plan for the West of the Netherlands. Its proposal highlights the importance of a flexible and strategic open planning framework and alternative "selection areas" for collaborative decision-making.

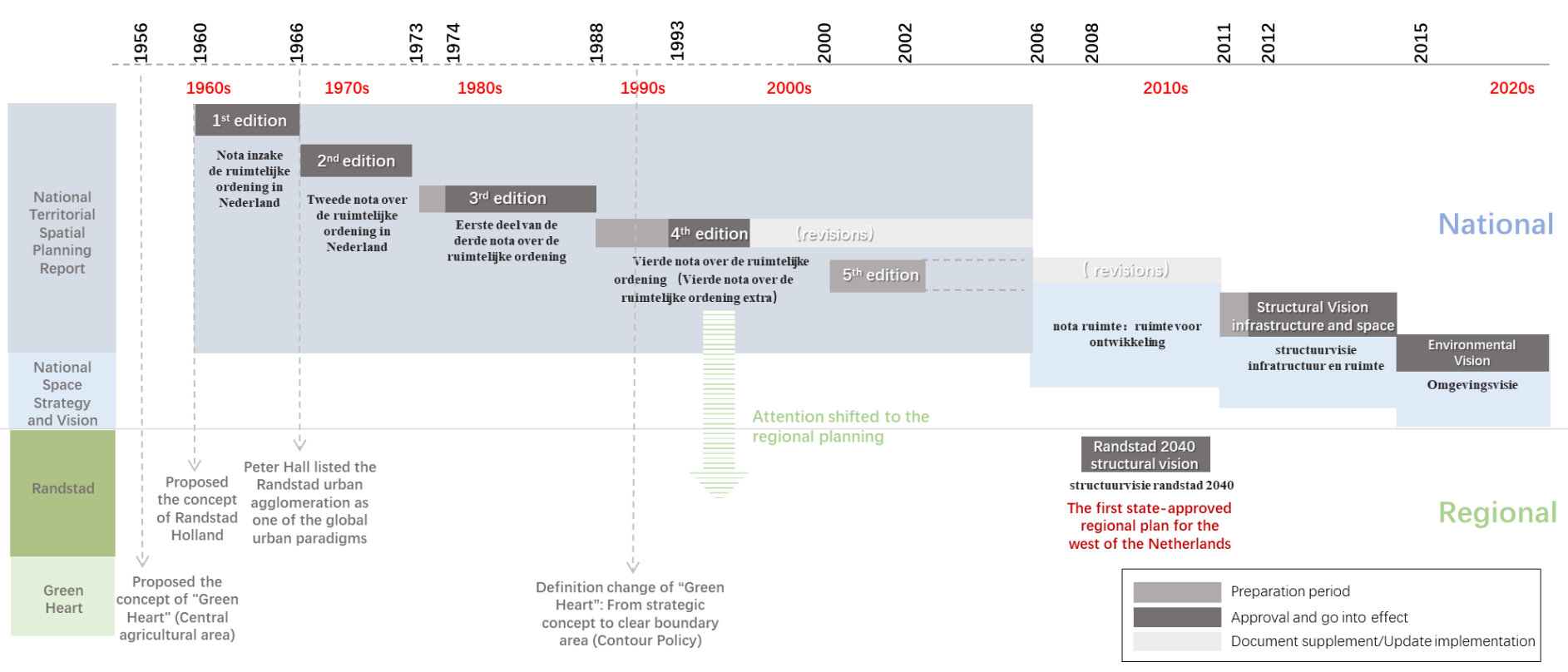

Figure 9 Changes of Randstad spatial planning. Source: by author

\subsection{Planning tool: heterogeneous spatial partitioning}

The Randstad region reasonably divides different functional areas according to the regional resource and environmental carrying capacity, existing development intensity and future development potential through national land and space planning to form a dislocation development and functionally complementary industrial division network between cities, thereby promoting the city Group environmental governance. The Dutch government attaches great importance to the planning and utilization of land in the Randstad area, and adopts a relatively strict industrial location policy, requiring that the spatial layout of various industries in this area must meet the requirements of land use planning, effectively alleviating the urban agglomeration Disorderly expansion. Different from the common and balanced development pattern formed in the history of China's Yangtze River Delta, most cities in the Randstad region have relatively single functions, and each city has a clear division of labor. The national policy regulates the overall industry in the Randstad region, and promotes the coordination of industry and population, ecology, and resources, so as to form a competitive regional space advantage under the sustainable goal. In addition, based on the multiple stakeholders of regional development, the Dutch government has established an open dialogue platform that coordinates the interests of all parties in the government and the market. By jointly formulating regional development goals, policies and plans, the Dutch government realizes coordinated actions, plans and arrangements, and promotes internal connections in regional spaces. 


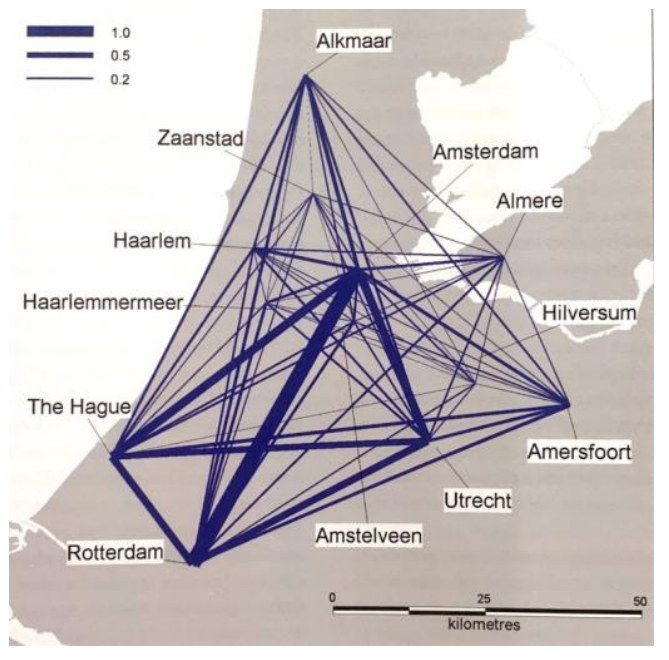

Figure 10 Intra-regional linkages through office networks. Source: reference (Hall, P. ; Pain, K., 2006)

\section{Discussion: Reflections on the governance structure of cross-border regional planning}

This paper synthesizes the regional environmental problems of the Yangtze River Delta in China since the 1950 s and the process of coordinated development of cross-border regions, and draws on the characteristics of cross-border planning for ecological goals in the Randstad region of the Netherlands, so as to form the following thoughts on the issues of China's cross-border regional planning.

\subsection{The dual division of planning and governance}

The phenomenon of "only planning without governance" is prominent. Through research, this article finds that "only planning without governance" has become the evil result of the division of government agencies' functions. For example, the dual division between the planning department and the environmental department has led to the prominent function of the planning department, which has become independent and unscrupulous. Similar to the planning department, when environmental issues are raised, all departments will jointly blame the environmental department's governance work. Under the guidance of their respective functional goals, the governance tasks of environmental departments have become "remedial governance", which can only continue to pay for urban construction under the leadership of multiple departments. As a guiding policy tool, planning should be an important part of governance, but it has become a technical product of the independence stage in the government process. Therefore, under the overall goal of facing the sustainable development of space ecology and environment, we should learn from the ideas of Dutch institutional reform and further integrate the functions of the environmental department and the planning department.

\subsection{The planning governance structure lacks horizontal cohesion}

As shown in Figure 11, the logical basis for the division of labor and governance in the Yangtze River Delta region is too dependent on tasks and target planning, and lacks overall regional thinking. For example, in the "Three-Year Action Plan", mission projects involving the construction of a transboundary ecological economic belt and a transboundary greenway network will clearly stipulate that the "responsible unit" of the three provinces and one city is the Development and Reform Commission(DRC) of city A and B, and Spatial Management Agency (SMA), Water Resources Agency(WRA), Environment and Ecology Agency (EEA) of each city, but lack a horizontal spontaneous inter-city cooperation linkage mechanism. For example, the Netherlands uses national territorial and spatial planning and non-governmental organizations to achieve horizontal cooperation between cities; France achieves horizontal adhesion through an intergovernmental agreement system. Therefore, the logic of collaborative governance in the 
Yangtze River Delta region has not undergone essential changes. The vertical regional planning governance structure has led to more functional issues of "collection work" than "mediation work" at the cross-border regional level, which is not conducive to promoting a collaborative governance action.

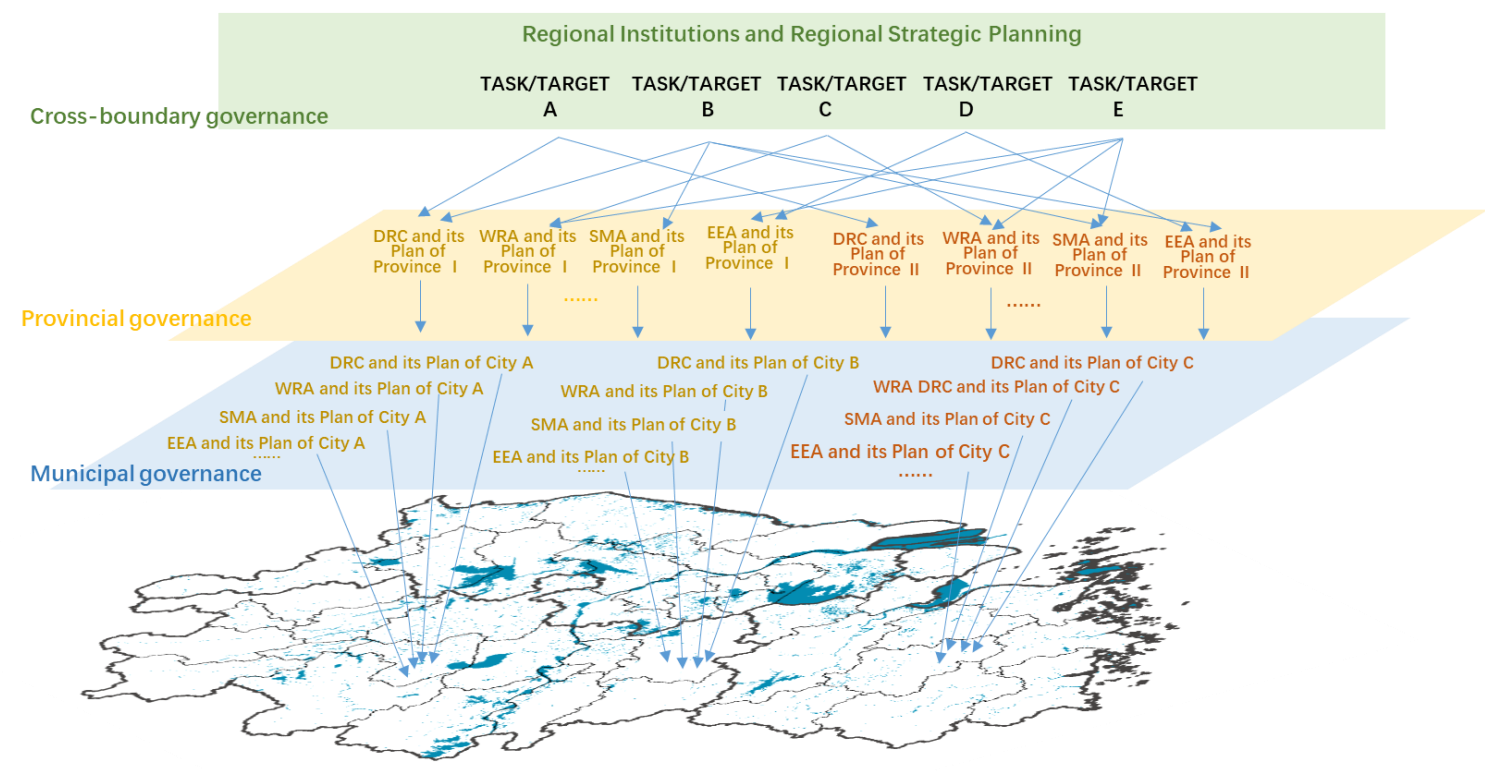

Figure 11 Stratification of planning governance structure in the Yangtze River Delta. Source: by author

\subsection{Hidden dangers in planning implementation}

Generally speaking, several versions of regional plans and local plans have been produced in the Yangtze River Delta, and there are various types of plans. As shown in Figure 12, the planning agencies, planning functions, planning types, and implementation tools involved in water environment governance matters have a complex occlusal relationship.

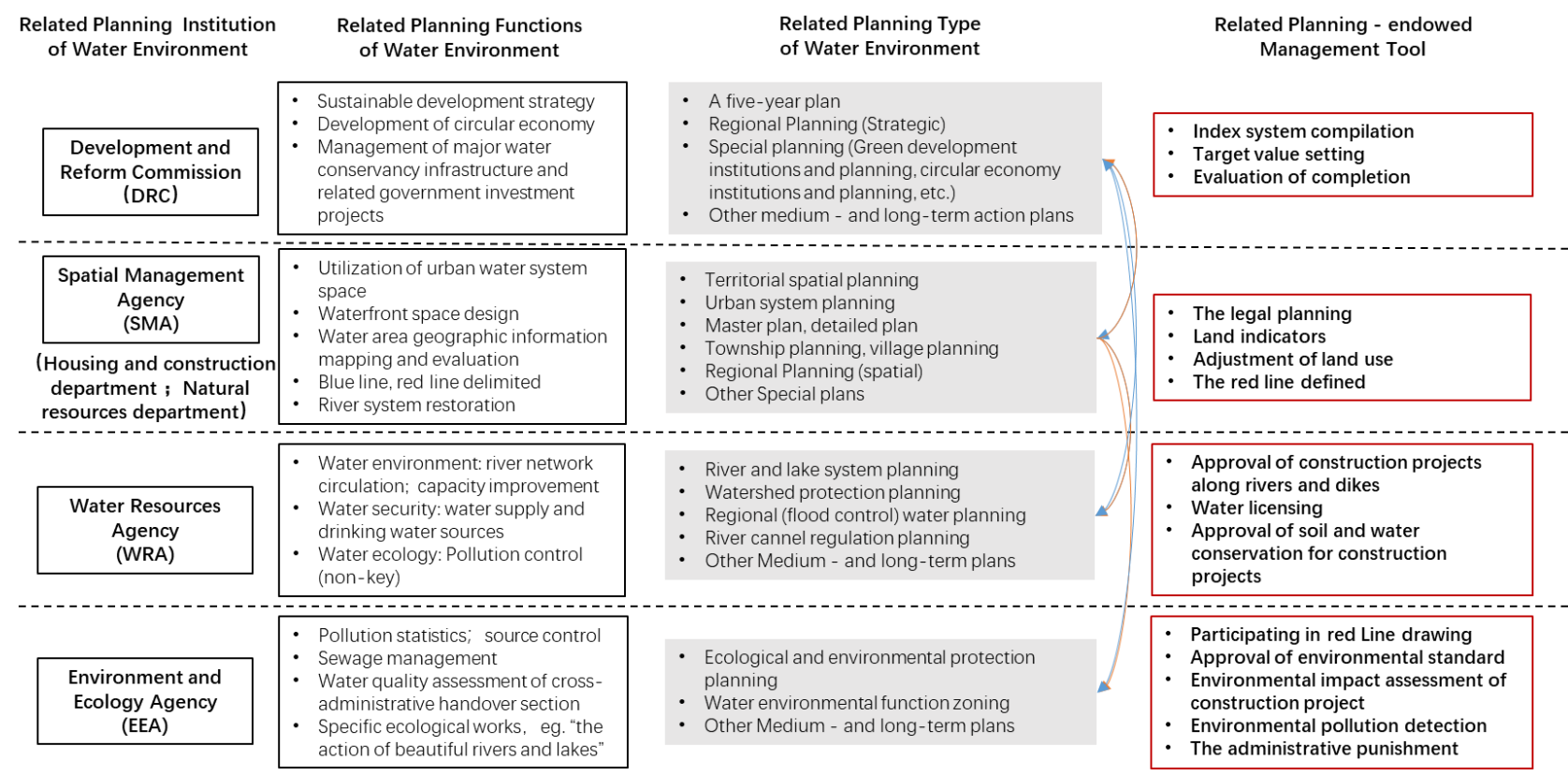

Figure 12 China's planning governance structure related to the water environment. Source: by author

Although the "multi-plan integration" work has entered the national policy agenda, at the local level, due to the different types of planning texts of various departments and the historical inconsistency of data 
sources and survey methods, the actual planning and integration work is facing practical difficulties. In addition, cross-border regional planning is always biased towards development planning, and local implementation focuses on formulating annual project plans, which is different from the planning system led by the national territorial and spatial planning in the Netherlands, and lacks integration with spatial elements. At the same time, the personnel of the regional cooperation agencies are transferred from various places, and the lack of participation and coordination at the national level has brought difficulties to the implementation of regional coordination tasks. A multi-level, multi-center planning and governance network has yet to be established.

\section{References}

Bodin, Örjan. (2017) Collaborative environmental governance: Achieving collective action in socialecological systems. Science (American Association for the Advancement of Science), 357(6352), p.eaan1114.

Bryson, J.M., Crosby, B.C. \& Stone, M.M. (2006) The Design and Implementation of Cross-Sector Collaborations: Propositions from the Literature. Public administration review, 66(s1), pp.44-55.

Deng Xiaojun, Xu Youpeng, et al. (2016) Spatial-temporal changes of river systems in Jiaxing under the background of urbanization. Acta geography sinica, 71(1), pp.75-85.

H.M.C.Dwarshuis-Van de Beek. (2010) Randstad monitor(mini version).

Hajer, M. \& Zonneveld, W. (2000) Spatial Planning in the Network Society-Rethinking the Principles of Planning in the Netherlands. European planning studies, 8(3), pp.337-355.

Han Longfei, Xu Youpeng, et al. (2015) Temporal and spatial change of stream structure in Yangtze RiverDelta and its driving forces during 1960s-2010s. Acta geography sinica, 70(5), pp.819-827.

Hendriks, F. (2006) Shifts in Governance in a Polycentric Urban Region: The Case of the Dutch Randstad. International Journal of Public Administration, 29(10-11), pp.931-951.

Hou Aimin. (2016) The construction and management of ecological environment from the perspective of power space. Nanjing: Southeast University Press.

Hu Wen, Huang Ling, et al. (2015) Introduction to urban planning. Wuhan: Huazhong University of Science and Technology Press.

Hu Xuwei. (1982) Territorial planning and regional planning. Economic geography, pp3-8.

Jessop B . (2003) Governance and meta-governance: On reflexivity, requisite variety and requisite irony.

Lambregts, B. \& Zonneveld, W.A.M. (2004) From Randstad to Deltametropolis: Changing attitudes towards the scattered metropolis. European planning studies, 12(3), European planning studies, Vol.12 (3).

Ministerie van VROM (Volkshuisvesting, Ruimtelijke Ordening en Milieubeheer) (2008) Structuurvisie Randstad 2040 [Randstad 2040 Structural Vision], Den Haag.

Ministry of Infrastructure and the Environment. (2013) Spatial Planning Calendar-75Years of National Spatial Policy in The Netherlands [S.I.] .

Peter Hall, Kathy Pain. (2006) The Polycentric Metropolis: Learning from Megacity Regions in Europe. London: Earthscan, 137-145.

Su Dong, Liu Jian. (2021)Path Selection for the Reform of Planning Management Agencies and Modernization of Spatial Governance in China. China City Planning Review, 30(1),pp.24-35. 
Van Bueren, E.M. \& Priemus, H. (2002) Institutional Barriers to Sustainable Construction. Environment and planning. B, Planning \& design., 29(1), pp.75-86.

Wang YM. (2017)The Experience of Environmental Cooperative Governance in the Urban Agglomeration of Randstad in the Netherlands .China Ancient City, 190(7), pp.85-90.

Whitehead, M. (2003) In the shadow of hierarchy': meta-governance, policy reform and urban regeneration in the West Midlands. Area (London 1969), 35(1), pp.6-14.

Zhang Xianchun, Long Di, Bian Fang. (2015) The Protection of "Green Heart" in Randstad: The Construction of Regional Coordination and the Innovation of Spatial Planning [J]. Urban Planning International, 30(5),pp.57-65.

Zonneveld, W. \& Spaans, M. (2014) Meta-governance and developing integrated territorial strategies: The case study of MIRT territorial agendas in the Randstad (Netherlands). Planning theory \& practice, 15(4), pp.543-562. 